\title{
The economic impact of invasive pest Drosophila suzukii on berry production in the Province of Trento, Italy
}

\author{
Giorgio De Ros ${ }^{\mathrm{a}, *}$, Sandro Conci ${ }^{\mathrm{a}}$, Tommaso Pantezzi ${ }^{\mathrm{a}}$ and Gianluca Savini ${ }^{\mathrm{b}}$ \\ ${ }^{a}$ Center for Technology Transfer, Fondazione Edmund Mach, San Michele all'Adige (TN), Italy \\ ${ }^{\mathrm{b}}$ Sant'Orsola Società Cooperativa Agricola, Pergine Valsugna (TN), Italy \\ Submitted 15 January 2015; accepted 19 March 2015
}

\begin{abstract}
.
BACKGROUND: The fly Drosophila suzukii (Matsumura) (Diptera: Drosophilidae) is an endemic pest, native to Southern Asia which has recently invaded western countries. Since its detection in 2008 in California and Spain, it is now established in North America and in many European countries.

OBJECTIVE: This paper aims to evaluate the pest's economic impact on the soft fruit industry in the Province of Trento, a region in the North East of Italy, which is one of the most productive soft fruit areas in Europe.

METHODS: The evaluation takes into account both the growers' potential revenue losses and the costs of pest control and uses a partial budgeting approach. Two scenarios are evaluated: the one before and the one after the implementation of an integrated control strategy for D. suzukii.

RESULTS: Before the adoption of an integrated pest control strategy, the estimated revenue losses amounted to about $13 \%$ of the industry's output. After the implementation of an integrated strategy this loss decreased to about 7\% of the industry's output. CONCLUSIONS: The adopted strategy seems effective in mitigating the pest's economic impact. The knowledge about D. suzukii's impact and its management would benefit from further analysis encompassing a larger geographical scope and longer time series.
\end{abstract}

Keywords: Drosophila suzukii, economic impact, partial budgeting, pest management, Italy

\section{Introduction}

The Drosophila suzukii fly (Matsumura) (Diptera: Drosophilidae) is an endemic pest to South Asia which has recently settled in western countries. Since its detection in 2008 in California [1] and Spain [2], it has become established in North America and in many European countries. Differently from most other Drosophila, D. suzukii lays eggs and feeds on unblemished ripening fruit of many plant species. Due also to the pest's ability to adapt to a wide range of climatic conditions, its high dispersal potential and rapid reproduction [3, 4], it poses a real threat for the fruit industries in the newly invaded countries.

Over time the species has demonstrated remarkable expansion trends. A wide range of crops have been affected and extensive damage has been recorded on berries and cherries in particular [3,5]. These trends have driven specific research projects on pest biology and control [cfr 3, 6], as well as instigating a comprehensive Pest Risk Analysis (PRA) performed by an Expert Working Group from the European and Mediterranean Plant Protection Organisation (EPPO) [7].

*Corresponding author: Giorgio De Ros, Center for Technology Transfer, Fondazione Edmund Mach, Via E. Mach 1, I-38010 San Michele all'Adige (TN), Italy. Tel.: +39 0461 615247; E-mail: giorgio.deros@ @mach.it. 
The International Standards for Phytosanitary Measures No 5, ISPM 5, define the risk as the "probability of introduction and spread of a pest and the magnitude of the associated potential economic consequences" for quarantine pests, or the "probability that a pest in plants for planting affects the intended use of those plants with an economically unacceptable impact " for non-quarantine pests [8, p17]. A PRA thus has to include an evaluation of the potential economic impact of the pest's invasion.

Concerning the assessment of the potential economic consequences of pest introduction, ISPM 5 state that "if a quantitative measure is not feasible, then this part of the assessment should include at least a qualitative analysis" [8, p28]. In fact the qualitative analysis is the default method for assessing the economic impact in a PRA: in the decision support scheme for PRAs adopted by EPPO [9], as well as in similar schemes used in other parts of the world [10], the potential economic impact is evaluated according to predefined ordinal scales. The assessment of potential economic consequences resulting from this approach, such as the PRA for D. suzukii [7], consists thus of broad qualitative statements (e.g. "massive" negative effects on crop yield and/or quality, "moderate" increase in production costs, etc.), without any quantification of the impact.

As is argued by Soliman et al. [10,11], methods based on expert judgements are inexpensive and make efficient use of expert knowledge, but they have relevant limits in terms of transparency and repeatability, since the assumptions underlying the assessments are usually implicit and expert-specific. Quantitative assessments require additional work and resources, but the assumptions underlying the evaluations have to be made explicit. Moreover, quantifying the economic impact of a pest may involve measuring the effectiveness of possible management strategies and assess whether a pest management program is economically viable or not.

This paper aims to evaluate the $D$. suzukii's economic impact on the berry industry in one of the most important production areas in Europe: the Province of Trento, or Trentino as it is commonly known, in the North East of Italy. Attempts to quantify the pest's economic impact are relatively scarce at the present time, and have been, until now, focused on the USA [1, 12], despite various swarms of pests detected in Europe. A first estimate in the Trentino area, carried out according to 2011 data [13], took into account only the producers' revenue losses. As control approaches were still being researched, no information was provided on the cost of limiting the damage caused by the pest infestation. With improved knowledge developed over time about the pest's ecology and control, an integrated pest management strategy has been created, based on mass trapping, field sanitation and insecticide applications [14]. Its implementation on an area-wide scale started in 2012. Thanks to the data recorded since this time, it is now possible to allow for both the growers' potential revenue losses and the pest control costs in two scenarios: pre- and postimplementation of an integrated control strategy for D. suzukii.

\section{Material and methods}

The increasing amount of scientific literature considering economic analyses of alien invasive species [cfr 15-18] offers a range of methodological tools that can be used for the evaluation of $D$. suzukii's impact. To keep to the framework presented by Born et al. [17], at least three methodological issues should be heeded in the economic analysis of alien invasive species: the field of application of the analysis, the range of impacts to be considered and the data used. The analytical approach adopted in this analysis will conform to these considerations.

\subsection{Field of application}

The study looks at the four host crops mostly affected by D. suzukii in the Province of Trento [13]: strawberries, raspberries, blackberries and blueberries. As an ex ante reference, i.e. the revenue generated by the industry in standard conditions, we considered the average output of the period 2007-09, namely the years prior to the detection of considerable damage to cultivated berries in the area and its economic impact [19]. This output was estimated according to the average prices of the last 3-year period: 2011-2013. Accordingly, the potential revenue of the soft fruit industry in Trentino can be calculated at around 22.5 MEUR (Table 1), almost half of which is due to strawberries.

In relation to the field of application, Born et al. [17] distinguish between evaluation studies aimed at raising general awareness through the assessment of overall damages and studies that can contribute to the decision making process regarding appropriate control strategies. Our analysis compares the economic impact pre- and post- implementation 
Table 1

Revenue potential of small fruit production in the Province of Trento

\begin{tabular}{|c|c|c|c|c|}
\hline & Area $(\mathrm{Ha})$ & Production $(\mathrm{t})$ & Price $(€ / \mathrm{kg})$ & Value $(€)$ \\
\hline Strawberry & 128 & 4,167 & 2.87 & $11,938,661$ \\
\hline Raspberry & 93 & 669 & 7.08 & $4,735,710$ \\
\hline Blackberry & 33 & 553 & 4.47 & $2,472,287$ \\
\hline Blueberry & 91 & 689 & 4.99 & $3,437,482$ \\
\hline Total & & & & $22,584,140$ \\
\hline
\end{tabular}

of a pest management strategy, thus it can serve as a basis for the ex post appraisal of the adopted strategy. This case history may also be useful for areas where a pest invasion is in an earlier phase.

\subsection{Range of impact}

According to the distinction widely accepted in scientific literature $[10,11,17,20]$ as well as in policy documents $[8,21]$, the impact of invasive pests may be direct or indirect. The direct impact reflects the immediate, host-specific effects on the production process, such as yield losses and additional production costs. The indirect impact is that generated downstream to the production process, or those effects that are (in a sense) non-host specific. The indirect impact includes general market effects like price changes and shifts in consumer demands, market access problems caused by export restrictions and the social impact, for example, the consequences on tourism and the environment such as a possible loss of biodiversity.

In the PRA for D. suzukii [7] the impact on crop yield and/or quality or on control cost was assigned the maximum score (e.g. "massive"), while the items demonstrating indirect market effects were given an intermediate score (e.g. "moderate" and "moderately likely", but with an high degree of uncertainty). The items showing environmental and social effects were allocated the lowest scores (e.g. "minor" and "minimal" respectively).

Our analysis is focused on the direct impact of D. suzukii, i.e. the specific effects on the host crops in terms of yield losses and associated control costs.

The indirect market effects generated by pest infestations may be twofold for producers: on one hand, key export countries could impose trade restrictions so that growers would either lose access to these markets or have to implement costly phytosanitary measures. On the other hand, the decrease in production caused by the pest could induce a price increase. The net effect of these considerations depends, among other things, on the relevance of exports: the more a productive system relies on exports, the more likely the net effect would be significantly negative. From this point of view, Italy is a net berry importer and the produce from the Province of Trento is sold predominantly (ca 95\% according to estimates) on the domestic market. All this considered, we choose not to take indirect trade effects into consideration, assuming in our case study a null or negligible net effect of both possible export restrictions and price increase.

In their analysis of the D. suzukii's impact on the California strawberry and raspberry industry, Goodhue et al. [12] calculated a positive price response to the yield losses, but they did not allow for any negative effect on the export market. This methodological choice may have led to an underestimation of the actual impact of the pest. Nonetheless its justification is well founded: large-scale export restrictions may be unlikely "since the majority of importing countries already have D. suzukii populations" [12, p.1402].

\subsection{Type of data}

Born et al. [17] underline that economic evaluation is conducted either to provide advice on a business level or to supply information to society as a whole. In order to assess social concerns, a broader level of assessment than mere business analysis would be needed. However, coherently with the results of the PRA for D. suzukii [7], this study aims to assess the pest's potential impact on the berry industry, and not on society as a whole. Accordingly, business data is used. 
As mentioned before, our study focuses on the assessment of direct impact, i.e. the potential damage caused by the pest's infestation and its management costs. The quantification of potential economic loss is based on the percentage of infected samples resulting from the grading process in a marketing co-op between 2011 and 2013. Evaluation of the pest management costs is carried out by considering the material (insecticides, food baits, etc.), the machinery and the labour costs incurred.

As recommended by Hallam et al. [22], defined market input costs are used whenever possible. Therefore the costs of material are valued at market prices, while for labour costs, the wages established in the collective agreement for agriculture were referred to. The hourly costs of machinery were computed, bearing in mind amortization costs, repair costs, as well as the fuel costs for towing vehicles.

\subsection{Analytical technique}

The International Standards for Phytosanitary Measures No 11 list three analytical techniques which can be used to assess the potential economic effects of a pest: partial budgeting, partial equilibrium and general equilibrium models [21]. The differences between these techniques in terms of complexity, resource requirements and scope of analysis are thoroughly discussed by Soliman et al. $[10,11]$. Partial budgeting takes into account the additional costs and revenue losses at the producer level. Partial equilibrium models quantify the price effects of changes in the production volumes in addition to further costs and revenue losses at the producer level. Computable general equilibrium models are based on systems of equations that look at the effects of the pest invasion on the whole economy.

Although partial budgeting does not enable consideration of all the possible economic consequences of a pest invasion, and can thus lead to underestimating the economic impact, this technique is rather commonly used in the research [1, 23-25]. As argued by Soliman at al. [11], simplicity and transparency are the strength of the partial budgeting method, which, despite its limitations, can be considered the default method of choice for basic economic analysis. Moreover ISPM 11 considers this technique as adequate when the economic effects of the pest are generally limited to the producers [21], as seems to be the case of D. suzukii's infestation of Trentino. Last but not least, the use of partial budgeting is consistent both with the outcomes of the PRA for D. suzukii [7] and with our approach concerning the range of impacts and type of data.

\section{Results and discussion}

\subsection{Impact before the implementation of an integrated management strategy}

In the absence of pest damage limitation, the economic impact is calculated solely by the industry's revenue loss caused by infected and non-marketable produce. In order to evaluate the potential damage in this scenario, the same methodology as in the previous study is adopted [13], i.e. calculating the weekly percentage of infected samples after grading by a soft fruit marketing co-op on the industry's potential output. Grading data from 2011 is used, the year prior to the implementation of a specific pest management strategy (Table 2).

Table 2

Potential revenue losses (Euros per year) before the implementation of an integrated control strategy

\begin{tabular}{lrrrrrr}
\hline & \multicolumn{5}{c}{ Harvesting weeks } \\
\cline { 2 - 6 } Crops & $20-27$ & $28-31$ & $32-35$ & $36-39$ & $40-43$ & TOTAL \\
\hline Strawberry & 2,489 & 31,106 & 229,049 & 137,651 & 26,490 & 426,784 \\
Raspberry & 13,364 & 51,855 & 332,088 & 127,492 & 19,609 & 31,178 \\
Blackberry & 658 & 61,792 & 218,235 & 149,315 & 1,049 & $1,430,286$ \\
Blueberry & 8,252 & 567,386 & 783,234 & 70,365 & $2,862,656$ \\
Total & & & & & \\
\hline
\end{tabular}




\subsection{Impact after the implementation of an integrated management strategy}

As mentioned previously, the adopted control strategy for D. suzukii includes mass trapping, field sanitation and additional insecticide applications. For each of these elements we first calculated unit costs per hectare, which were then multiplied for the harvested area. The area cultivated with early ripening blueberry cultivars, that are harvested before the pest is active and thus would not need additional control costs [26], are not taken into account.

After proving their effectiveness as a control method in field experimentations, traps have been distributed by berry co-ops to their associates since 2012. The traps have to be placed around the field borders, at an estimated average of 250 traps per ha, and re-filled every week during the whole harvest period with a food bait named Droskidrink [27]. The re-fill of the traps requires $20 \mathrm{cl}$ of Droskidrink $(0.2 €)$ and 2 minutes labour. Given a harvest period varying from 5 to 12 weeks, depending on the different cultures, the total yearly cost of mass trapping is calculates on the basis of an average labour cost of $7.5 € / \mathrm{h}$ (Table 3 ).

A second component of the D. suzukii control strategy in Trentino is the field clean-up. Any fruit that remains in the crop can be a source for re-infestation by $D$. suzukii. Therefore every rejected piece of fruit has to be removed from the field and destroyed on a daily basis during harvest. This practice requires additional work that can be estimated at around 1 hour per ha for each harvest day. Total sanitation costs are calculated taking into consideration the different harvest periods for the different varieties of fruit (longer, for instance, for ever bearing strawberries, shorter for June bearing strawberries) and at an average labour cost of $7.5 € / \mathrm{h}$ (Table 4 ).

Chemical control is another crucial element of the pest management strategy. For the producers it implies an increase of insecticides and application costs. Specific insecticide treatments for D. suzukii, and their application rates according to the guidelines of the local Extension Service, are evaluated on the basis of market prices (Table 5).

The application costs vary according to the type of machinery used. We hypothesized three standard levels of mechanisation and the related hourly costs. On the basis of the different levels of mechanisation of local farms, and the area cultivated by the different types of farm, application costs are evaluated for the whole industry (Table 6).

Table 3

Mass trapping costs

\begin{tabular}{|c|c|c|c|c|c|c|c|c|}
\hline & \multirow[b]{2}{*}{ Traps (nr/Ha) } & \multicolumn{3}{|c|}{ Material (Food baits) } & \multicolumn{2}{|c|}{ Labour } & \multirow[b]{2}{*}{ Area $(\mathrm{Ha})$} & \multirow[b]{2}{*}{ Costs $(€)$} \\
\hline & & Unit. Cost (€) & Changes (nr) & Cost $(€ / \mathrm{Ha})$ & Time $(\mathrm{min} / \mathrm{Ha})$ & Cost $(€ / \mathrm{Ha})$ & & \\
\hline Strawberry (Junebear) & 250 & 0.2 & 5 & 250 & 1875 & 234.36 & 64 & 31,000 \\
\hline Strawberry (Everbear) & 250 & 0.2 & 12 & 600 & 4500 & 562.50 & 64 & 74,400 \\
\hline Raspberry & 250 & 0.2 & 7 & 350 & 2625 & 328.13 & 93 & 63,066 \\
\hline Blackberry & 250 & 0.2 & 7 & 350 & 2625 & 328.13 & 33 & 22,378 \\
\hline Blueberry & 250 & 0.2 & 5 & 250 & 1875 & 234.38 & 70 & 33,906 \\
\hline Total & & & & & & & & 224,730 \\
\hline
\end{tabular}

Table 4

Sanitation costs

\begin{tabular}{|c|c|c|c|c|c|}
\hline & $\begin{array}{c}\text { Labour } \\
\text { (hrs/day/Ha) }\end{array}$ & $\begin{array}{l}\text { Hourly wage } \\
(€ / h)\end{array}$ & $\begin{array}{l}\text { Harvesting } \\
\text { (nr of days) }\end{array}$ & $\begin{array}{l}\text { Area } \\
(\mathrm{Ha}) \\
\end{array}$ & $\begin{array}{c}\text { Costs } \\
(€)\end{array}$ \\
\hline Strawberry (Junebear) & 1 & 7.5 & 45 & 64 & 21,600 \\
\hline Strawberry (Everbear) & 1 & & 75 & 64 & 36,000 \\
\hline Raspberry & 1 & & 75 & 93 & 52,313 \\
\hline Blackberry & 1 & & 75 & 33 & 18,563 \\
\hline Blueberry & 1 & & 45 & 70 & 23,625 \\
\hline Total & & & & & 152,100 \\
\hline
\end{tabular}


Table 5

Insecticide costs

\begin{tabular}{|c|c|c|c|c|c|c|}
\hline & \multirow[b]{2}{*}{ Treatment } & \multicolumn{2}{|c|}{ Application rate } & \multirow[b]{2}{*}{ Cost (€/ha) } & \multirow[b]{2}{*}{ Area (ha) } & \multirow[b]{2}{*}{ Costs $(€)$} \\
\hline & & $\mathrm{cl} / \mathrm{hl}$ & $\mathrm{hl} / \mathrm{ha}$ & & & \\
\hline \multirow[t]{2}{*}{ Strawberry } & deltamethrin & 50 & 15 & 35.3 & 128 & 4,518 \\
\hline & lambda-cyalothrin & 25 & 15 & 60.0 & & 7,680 \\
\hline \multirow[t]{2}{*}{ Raspberry } & deltamethrin & 50 & 15 & 70.6 & 93 & 6,566 \\
\hline & spinosad & 25 & 15 & 180.0 & & 16,740 \\
\hline \multirow[t]{2}{*}{ Blackberry } & deltamethrin & 50 & 15 & 105.9 & 33 & 2,330 \\
\hline & spinosad & 25 & 15 & 180.0 & & 5,940 \\
\hline Blueberry & phosmet & 250 & 15 & 223.5 & 70 & 15,645 \\
\hline Total & & & & & & 59,419 \\
\hline
\end{tabular}

Table 6

Application costs

\begin{tabular}{|c|c|c|c|c|c|c|c|c|c|c|c|}
\hline & \multirow[b]{2}{*}{$\begin{array}{c}\text { Applications } \\
\text { (nr/year) }\end{array}$} & \multicolumn{3}{|c|}{ Heavy mechanisation } & \multicolumn{3}{|c|}{ Light mechanisation } & \multicolumn{3}{|c|}{ No mechanisation } & \multirow[b]{2}{*}{$\begin{array}{c}\text { Costs } \\
(€) \\
\end{array}$} \\
\hline & & $\begin{array}{l}\text { Time } \\
\text { (hrs) }\end{array}$ & $\begin{array}{l}\text { Unit. Cost } \\
(€ / \mathrm{h})\end{array}$ & $\begin{array}{l}\text { Area } \\
\text { (ha) }\end{array}$ & $\begin{array}{l}\text { Time } \\
\text { (hrs) }\end{array}$ & $\begin{array}{l}\text { Unit. Cost } \\
\quad(€ / \mathrm{h})\end{array}$ & $\begin{array}{l}\text { Area } \\
\text { (ha) }\end{array}$ & $\begin{array}{l}\text { Time } \\
\text { (hrs) }\end{array}$ & $\begin{array}{l}\text { Unit. Cost } \\
\quad(€ / \mathrm{h})\end{array}$ & $\begin{array}{l}\text { Area } \\
\text { (ha) }\end{array}$ & \\
\hline Strawberry & 2 & 2 & 35.26 & 108.8 & 7.5 & 24.84 & 6.4 & 9 & 12.29 & 12.8 & 20,564 \\
\hline Raspberry & 3 & & & 79.0 & & & 4.7 & & & 9.3 & 22,428 \\
\hline Blackberry & 3 & & & 28.0 & & & 1.7 & & & 3.3 & 7.970 \\
\hline Blueberry & 1 & & & 59.5 & & & 3.5 & & & 7.0 & 5.623 \\
\hline Total & & & & & & & & & & & 56,585 \\
\hline
\end{tabular}

Table 7

Potential revenue losses (Euros per year) after the implementation of an integrated control strategy

\begin{tabular}{|c|c|c|c|c|c|c|}
\hline \multirow[b]{2}{*}{ Crops } & \multicolumn{6}{|c|}{ Harvesting weeks } \\
\hline & $20-27$ & $28-31$ & $32-35$ & $36-39$ & $40-43$ & TOTAL \\
\hline Strawberry & 2,475 & 50,535 & 91,560 & 19,718 & 7,213 & 171,501 \\
\hline Raspberry & 4,786 & 22,415 & 52,898 & 54,641 & 18,657 & 153,397 \\
\hline Blackberry & 851 & 22,951 & 98,038 & 104,181 & 19,232 & 245,253 \\
\hline Blueberry & 2,812 & 193,335 & 266,884 & 23,977 & 357 & 487,365 \\
\hline Total & & & & & & $1,057,516$ \\
\hline
\end{tabular}

Finally, after implementation of the integrated management strategy of $D$. suzukii, in 2012 and 2013 the damage on fruit production did decrease, but not to zero. In fact, the potential damage amounted to about 1,000,000 Euro (Table 7), taking into account the average percentage of infected samples in the grading during the two-year period 2012-13.

\section{Conclusions}

Assessing the impact of an invasive pest is per se an imprecise task. The present evaluation aims to gauge a conservative estimate, taking into account only the potential revenue losses of the Province of Trento small fruit industry and the associated control costs. Coherently with the Pest Risk Assessment performed by EPPO [7], no 
Table 8

Comparison of the economic impact of D. suzukii on soft fruit industry in Trentino before and after the implementation of an integrated management strategy

\begin{tabular}{lcc}
\hline Scenario & $\begin{array}{c}\text { Economic impact } \\
(€)\end{array}$ & $\begin{array}{c}\text { Economic impact } \\
\text { (\% of potential revenue) }\end{array}$ \\
Before management strategy & & $12,68 \%$ \\
Potential revenue losses & $2,862,656$ & $12,68 \%$ \\
TOTAL & $2,862,656$ & $1,00 \%$ \\
After management strategy & & $0,67 \%$ \\
Mass trapping costs & 224,730 & $0,26 \%$ \\
Field clean-up costs & 152,100 & $0,25 \%$ \\
Treatment costs & 59,419 & $4,68 \%$ \\
Application costs & 56,585 & $6,86 \%$ \\
Potential revenue losses & $1,057,516$ & \\
Total & $1,550,350$ & \\
\hline
\end{tabular}

societal externalities are considered. Concerning the indirect trade impacts, the net effect of possible export restrictions and price increase is assumed negligible.

The conservative nature of our assessment highlights the fact that the D. suzukii infestation has had a dramatic economic impact on soft fruit production in the Province of Trento. Before the adoption of an integrated management strategy, the potential revenue losses could be quantified at about $13 \%$ of the industry's output. After the implementation of an integrated strategy, the sum of revenue losses and associated control costs amounts to about $7 \%$ of industry's output (Table 8). The adopted strategy seems therefore effective in mitigating the pest's economic impact. Nonetheless the knowledge about $D$. suzukii's impact and its management would benefit from further analysis encompassing a larger geographical scope and longer time series.

\section{Acknowledgments}

The authors would like to thank Alberto Grassi, Claudio Ioriatti and Ermanno Cetto for their inputs in the early phase of the study, the anonymous reviewers for the helpful comments on a first version of this paper, Jayne Tomlins for the proof reading. This work was partially supported by the Autonomous Province of Trento (Italy), Research funds for Grandi Progetti, Project LExEM (Laboratory of excellence for epidemiology and modeling, http://www.lexem.eu).

\section{References}

[1] Bolda M, Goodhue RE, Zalom FG. Spotted wing drosophila: Potential economic impact of a newly established pest. Agricultural and Resource Economics Update. 2010;13(3):5-8. Available from: http://giannini.ucop.edu/media/are-update/files/articles/v13n3_2.pdf

[2] Calabria G, Máca J, Bächli G, Serra L, Pascual M. First records of the potential pest species Drosophila suzukii (Diptera: Drosophilidae) in Europe. J Appl Entomol. 2012;136(1-2):139-47. doi: 10.1111/j.1439-0418.2010.01583.x

[3] Cini A, Ioriatti C, Anfora G. A review of the invasion of Drosophila suzukii in Europe and a draft research agenda for integrated pest management. Bull Insectology. 2012;65(1):149-60.

[4] Rota-Stabelli O, Blaxter M, Anfora G. Quick guide: Drosophila suzukii. Curr Biol. 2013;23(1):R8-R9. doi: 10.1016/j.cub.2012.11.021

[5] Walsh DB, Bolda MP, Goodhue RE, Dreves AJ, Lee J, Bruck Dj, et al. Drosophila suzukii (Diptera: Drsosphilidae): Invasive Pest of Ripening Soft Fruit Expanding its Geographic Range and Damage Potential. J Integ Pest Mngmt. 2011;2(1):1-7. doi: http://dx.doi.org/10.1603/IPM10010

[6] Dreves AJ. IPM program development for an invasive pest: Coordination, outreach and evaluation. Pest Manag Sci. 2011;67(11):1403-10. doi: $10.1002 / \mathrm{ps} .2266$

[7] European and Mediterranean Plant Protection Organisation (EPPO). Pest Risk Analysis for: Drosophila suzukii. EPPO, 2010. Available from: http://www.eppo.int/QUARANTINE/Pest_Risk_Analysis/PRAdocs_insects/11-17189_PRA_record_Drosophila_suzukii_ final\%20.pdf 
[8] International Standard for Phytosanitary Measures No 5 (ISPN 5). Glossary of Phytosanitary Terms. Rome, International Plant Protection Convention, FAO; 2013. Available from: https://www.ippc.int/publications/glossary-phytosanitary-terms

[9] European and Mediterranean Plant Protection Organisation (EPPO). Guidelines on Pest Risk Analysis, Decision-support scheme for quarantine pests Version No 5. EPPO, 2011. Available from: http://archives.eppo.int/EPPOStandards/PM5_PRA/PRA_scheme_2011.doc

[10] Soliman T, Mourits MCM. Oude Lansink AGJM, van der Werf W. Quantitative economic impact assessment of invasive plant pests: What it does require and when is it worth the effort? Crop Prot. 2015;69:9-17. doi:dx.doi.org/10.1016/j.cropro.2014.11.011

[11] Soliman T, Mourits MCM. Oude Lansink AGJM, van der Werf W. Economic impact assessment in pest risk analysis. Crop Prot. 2010;29:51724. doi:10.1016/j.cropro.2009.12.014

[12] Goodhue RE, Bolda M, Farnsworth D, Williams, JC, Zalom F.G. Spotted wing drosophila infestation of California strawberries and raspberries: Economic analysis of potential revenue losses and control costs. Pest Manag Sci. 2011;67(11):1396-402. doi: 10.1002/ps.2259

[13] De Ros G, Anfora G, Grassi A, Ioriatti C. The potential economic impact of Drosophila suzukii on small fruits production in Trentino (Italy). IOBC-WPRS Bull. 2013;91:317-21.

[14] Vitagliano S, Grassi A, Anfora G, Angeli S. L'insetto esotico Drosophila suzukii: Ecologia e linee di difesa. Italus Hortus. 2013 ;20(3):3-17.

[15] Pimentel D, McNair S, Janecka J, Wightmann J, Simmonds C, O’Connell C, et al. Economic and environmental threats of alien plant, animal, and microbe invasion. Agr Ecosyst Environ. 2001; 84:1-20.

[16] Pimentel D, Zuniga R, Morrison D. Update on the environmental and the economic costs associated with alien-invasive species in the United States. Ecolog Econ. 2005;52(3):273-88. doi:10.1016/j.ecolecon.2004.10.002

[17] Born W, Rauschmayer F, Bräuer I. Economic evaluation of biological invasions - a survey. Ecolog Econ. 2005;55(3):321-36.

[18] Olson LJ. The economics of terrestrial invasive species: A review of the literature. Agr Res Econom Rev. 2006;35(1):178-94.

[19] Grassi A, Palmieri L, Giongo L. Drosophila (Sophophora) suzukii (Matsamura), new pest of soft fruits in Trentino (North-Italy) and in Europe. IOBC-WPRS Bull. 2011;70:121-8.

[20] Evans EA. Economic Dimensions of Invasive Species. Choices: The Magazine of Food, Farm and Resource Issues. 2003;18(2):5-10.

[21] International Standard for Phytosanitary Measures No 11 (ISPN 11). Pest Risk Analysis for Quarantine Pests. Rome, International Plant Protection Convention, FAO; 2013. Available from: https://www.ippc.int/publications/pest-risk-analysis-quarantine-pests

[22] Hallam A, Eidman VR, Morehart M, Klonsky K, editors. Commodity Costs and Returns Estimation Handbook: A Report of the Aaea Task Force on Commodity Costs and Returns. Ames, IA: Iowa State University, Department of Economics; 1998.

[23] MacLeod A, Head J, Gaunt A. An assessment of the potential economic impact of Thrips palmi on horticolture in England and the significance of a successful eradication campaign. Crop Prot. 2004;23(7):601-10. doi:10.1016/j.cropro.2003.11.010

[24] Zalucki PM, Shabbir A, Silva R, Adamson D, Shu-Sheng L, Furlong MG. Estimating the Economic Cost of One of the World's Major Insect Pests, Plutella xylostella (Lepidoptera: Plutellidae): Just How Long Is a Piece of String? J Econ Entomol. 2012;104(5):1115-29. doi: http://dx.doi.org/10.1603/EC12107

[25] Brown P, Daigneault A. Cost-Benefit Analysis of Managing the Papuana uninodis (Coleoptera: Scarabaeidae) Taro Beetle in Fiji. J Econ Entomol. 2014;107(5):1866-77. doi: http://dx.doi.org/10.1603/EC14212

[26] Hampton E, Koski C, Barsonian O, Faubert H, Cowles RS, Alm SR. Use of Early Ripening Cultivars to Avoid Infestation and Mass Trapping to Manage Drosophila suzukii (Diptera: Drosophilidae) in Vaccinum corymbosum (Ericales: Ericaceae). J Econ Entomol. 2014;107(5): 1849-57.

[27] Grassi A, Anfora G, Maistri S, Maddalena G, De Cristofaro A, Savini G, et al. Development and efficacy of Droskidrink, a food bait for trapping Drosophila suzukii. In: IOBC Working Group "Integrated Production of Fruit Crops", Subgroup "Soft Fruits". VIII Workshop on Integrated Soft Fruit Production, Book of abstracts, 2014 May 26-28; Vigalzano di Pergine (TN), Italy. 105-106. 